\title{
Risk of exposure of a selected rural population in South Poland to allergenic mites. Part II: acarofauna of farm buildings
}

\author{
Krzysztof Solarz ${ }^{1}$ (D) Celina Pająk ${ }^{2}$
}

Received: 5 September 2018 / Accepted: 27 February 2019 / Published online: 5 March 2019

(c) The Author(s) 2019

\begin{abstract}
Exposure to mite allergens, especially from storage and dust mites, has been recognized as a risk factor for sensitization and allergy symptoms that could develop into asthma. The aim of this study was to investigate the occurrence of mites in debris and litter from selected farm buildings of the Małopolskie province, South Poland, with particular reference to allergenic and/or parasitic species as a potential risk factor of diseases among farmers. Sixty samples of various materials (organic dust, litter, debris and residues) from farm buildings (cowsheds, barns, chaff-cutter buildings, pigsties and poultry houses) were subjected to acarological examination. The samples were collected in Lachowice and Kurów (Suski district, Małopolskie). A total of 16,719 mites were isolated including specimens from the cohort Astigmatina (27 species) which comprised species considered as allergenic (e.g., Acarus siro complex, Tyrophagus putrescentiae, Lepidoglyphus destructor, Glycyphagus domesticus, Chortoglyphus arcuatus and Gymnoglyphus longior). Species of the families Acaridae (A. siro, A. farris and A. immobilis), Glycyphagidae (G. domesticus, $L$. destructor and L. michaeli) and Chortoglyphidae (C. arcuatus) have been found as numerically dominant among astigmatid mites. The majority of mites were found in cowsheds (approx. 32\%) and in pigsties (25.9\%). The remaining mites were found in barns (19.6\%), chaff-cutter buildings (13.9\%) and poultry houses (8.8\%). The results suggest that the allergenic mites may constitute an occupational hazard for agricultural workers in all farming environments examined.
\end{abstract}

Keywords Storage mites $\cdot$ Acaridae $\cdot$ Glycyphagoidea $\cdot$ Pyroglyphidae $\cdot$ Litter

Krzysztof Solarz

solarzk@sum.edu.pl

1 Department of Parasitology, Faculty of Pharmacy with the Division of Laboratory Medicine in Sosnowiec, Medical University of Silesia in Katowice, Jednosci 8, 41-218 Sosnowiec, Poland

2 Department of Biochemistry and Molecular Biology, Faculty of Health Sciences, University of Bielsko-Biala, Willowa 2, 43-300 Bielsko-Biala, Poland 


\section{Introduction}

Storage mites, especially several species from the families Acaridae, Glycyphagidae and Chortoglyphidae (Acari: Sarcoptiformes, Astigmatina), are commonly found in stored food products, hay, straw, granaries, barns and other farming and occupational environments, in dust from railway freight wagons, as well as in samples of house dust. The most abundant mites are Acarus siro, Acarus farris, Tyrophagus longior and Tyrophagus putrescentiae from Acaridae, Lepidoglyphus destructor and Glycyphagus domesticus from Glycyphagidae and Chortoglyphus arcuatus from Chortoglyphidae (Boström et al. 1997; Franz et al. 1997; Mehl 1998; Sánchez-Ramos et al. 2004, 2007; Pike and Wickens 2008; Wong et al. 2011; Solarz 2012). These mites were identified as a source of clinically important allergens, causing occupational allergy (known as allergy to storage mites) among farmers, grain-storage workers and other agricultural workers (Fain et al. 1990; Revsbech and Dueholm 1990; van Hage-Hamsten and Johansson 1998). These mites cause IgE-mediated sensitization among the above-mentioned occupational populations, who develop asthma, rhinitis and conjunctivitis when exposed to organic dust containing mite allergens (Arlian 2002; Sánchez-Ramos et al. 2004; Berger et al. 2005; Solarz 2012).

The aim of this study was to investigate the occurrence of mites in debris and litter from selected farms of the Małopolskie province, South Poland, with particular reference to allergenic and/or parasitic species as a potential risk factor of diseases among farmers.

\section{Materials and methods}

The study was carried out from May 2011 to September 2012. A total of 60 samples of materials collected from four farms in two locations (Lachowice and Kurów) on the territory of the Suski district (Stryszawa and vicinity, Małopolskie) were examined as the potential sources of the allergenic and/or parasitic mites in the farming environments (Table 1). All samples were collected into plastic bags of 11 capacity. These samples were sweepings containing organic dust, litter, debris, residues and other materials from certain farming environments. Generally 12 cowsheds, barns, pigsties, chaff-cutter buildings and poultry houses were analyzed for the occurrence of mites, including allergenic and/or parasitic taxa (Table 1). The mites were extracted using the Berlese method and preserved in $75 \%$ ethanol. For identification, all mites were mounted in Faure's medium on microscope slides, with the aid of the Olympus Europe Highlight 2100 stereomicroscope. All mite specimens collected were examined using differential interference contrast (Nomarski

Table 1 Summary statistics: number of samples collected from the particular farm buildings examined on the territory of Stryszawa and vicinity (Małopolskie province, South Poland)

\begin{tabular}{llllll}
\hline Farming environments & Barns & Pigsties & Cowsheds & Poultry houses & $\begin{array}{l}\text { Chaff- } \\
\text { cutter } \\
\text { buildings }\end{array}$ \\
\hline No. samples examined & 12 & 12 & 12 & 12 & 12 \\
No. mites collected & 3271 & 4321 & 5341 & 1465 & 2321 \\
$\%$ of total count & 19.56 & 25.85 & 31.95 & 8.76 & 13.88 \\
No. mites per sample & 109.03 & 144.03 & 198.03 & 48.83 & 77.37 \\
\hline
\end{tabular}


DIC) (under a Zeiss Axioskope 2 plus light microscope) and phase contrast optics (under a Olympus $\mathrm{CH} 40$ light microscope). Mites were identified using descriptions of taxa and the following publications: Hughes (1976), Baker (1999), Zhang and Fan (2005), Fan and Zhang (2007), Colloff (2009), Krantz and Walter (2009) and Solarz (2012). The results were expressed as the number of mites per $g$ of sample (wet weight). Mite abundance was also calculated as the number of specimens per sample.

Data were analyzed using $\chi^{2}$ tests in CSS-STATISTICA for Windows v.12 $(\alpha=0.05)$.

\section{Results}

\section{Overall results}

Species composition and dominance of the total mite fauna in samples from all types of farm buildings is listed in Table 2, whereas the abundance of allergenic acarofauna from particular types of farm buildings is given in Table 1 . The weight of the samples ranged between 11.08 and $36.91 \mathrm{~g}($ mean $=17.92 \pm 6.86 \mathrm{~g}$; median=15.70 g). Mites were found in all samples examined - in total 16,719 mite specimens were isolated and 27 species were identified (Table 2). Most mites were found in cowsheds (approx. 32\% of the total count) and in pigsties (25.9\%), followed by barns (19.6\%), chaff-cutter buildings (13.9\%) and poultry houses (8.8\%; Table 1). Samples were dominated by mites of the subfamilies Acaroidea and Glycyphagoidea. In addition, two species of pyroglyphid mites (Astigmatina) were collected (Gymnoglyphus longior and Hirstia chelidonis), as well as some members of Prostigmata (Cheyletidae, Tydeidae, Cunaxidae), Oribatida sensu lato and Mesostigmata (Table 2).

Species composition, frequency, dominance and abundance (numbers per $\mathrm{g}$ or per sample) of the acarofauna varied considerably between particular types of farm buildings examined (Tables 3, 4). Generally, the dominant species were A. siro $(\mathrm{n}=5065 ; 30.3 \%$ of all mites), A. farris $(\mathrm{n}=2009 ; 12.0 \%)$ and Acarus immobilis $(\mathrm{n}=1265 ; 7.6 \%)$ of the family Acaridae (Astigmatina), and two species from the family Glycyphagidae (Astigmatina) - G. domesticus $(\mathrm{n}=2051 ; 12.3 \%)$ and L. destructor (1790; 10.7\%) (Table 2). Among the relatively numerous mites were cheyletids (Prostigmata) $(1186 ; 7.1 \%)$ and some other astigmatid and potentially allergenic mites-T. putrescentiae $(661 ; 3.95 \%)$ and Acarus nidicolous (534; 3.2\%) from Acaridae, and Lepidoglyphus michaeli $(562 ; 3.4 \%)$ and $C$. arcuatus $(533 ; 3.2 \%)$ from Glycyphagoidea (Table 2). Other storage mites-T. longior, Tyrolichus casei, Mycetoglyphus fungivorus, Aleuroglyphus ovatus, Calogyphus berlesei, Rhizoglyphus spp. (all Acaridae), Lepidoglyphus fustifer, Glycyphagus privatus, Glycyphagus ornatus, Ctenoglyphus plumiger, Ctenoglyphus canestrinii and Diamesoglyphus intermedius (all Glycyphagidae)—were generally less abundant, as were the two pyroglyphids, G. longior and H. chelidonis.

Acarus siro, $G$. domesticus and $L$. destructor were also the most frequent mites in samples from the examined farm buildings with relative frequency 85.3, 66.7 and $66.0 \%$, respectively (Table 2). The difference in frequency between $A$. siro and the two glycyphagids was significant ( $\chi^{2}$ test: $p<0.005$, in both cases). Acarus siro was the most frequent mite in almost all farm building types examined-only in poultry houses it was preceded by $L$. destructor; in cowsheds both species occurred with the same frequency (Table 3). The frequency of $A$. siro was highest in chaff-cutter buildings (100\%) and in pigsties (93\%). This species was significantly more frequent in chaff-cutter buildings than in cowsheds, 
Table 2 Species list, dominance, abundance and frequency of mites found in samples from the various types of farm buildings combined, situated on the territory of Stryszawa and vicinity (Małopolskie)

\begin{tabular}{|c|c|c|c|c|}
\hline \multirow[t]{2}{*}{ Mite taxa } & \multicolumn{2}{|c|}{ Dominance } & \multicolumn{2}{|c|}{ Frequency } \\
\hline & $\mathrm{N}$ & $\mathrm{D}(\%)$ & $\mathrm{n}$ & $\mathrm{F}(\%)$ \\
\hline Acarus siro & 5065 & 30.29 & 128 & 85.33 \\
\hline Acarus farris & 2009 & 12.02 & 73 & 48.66 \\
\hline Acarus immobilis & 1265 & 7.57 & 49 & 32.66 \\
\hline Acarus nidicolous & 534 & 3.19 & 11 & 7.33 \\
\hline Acarus gracilis & 8 & 0.05 & 3 & 2.00 \\
\hline Tyrophagus putrescentiae & 661 & 3.95 & 42 & 28.00 \\
\hline Tyrophagus longior & 55 & 0.33 & 17 & 11.33 \\
\hline Tyrolichus casei & 4 & 0.02 & 1 & 0.66 \\
\hline Mycetoglyphus fungivorus & 3 & 0.02 & 1 & 0.66 \\
\hline Aleroglyphus ovatus & 1 & 0.01 & 1 & 0.66 \\
\hline Sancassania berlesei & 4 & 0.02 & 1 & 0.66 \\
\hline Rhizoglyphus echinopus & 2 & 0.01 & 1 & 0.66 \\
\hline Rhizoglyphus robinii & 2 & 0.01 & 1 & 0.66 \\
\hline Lepidoglyphus destructor & 1790 & 10.71 & 99 & 66.00 \\
\hline Lepidoglyphus michaeli & 562 & 3.36 & 31 & 20.66 \\
\hline Lepidoglyphus fustifer & 259 & 1.55 & 18 & 12.00 \\
\hline Glycyphagus domesticus & 2051 & 12.27 & 100 & 66.66 \\
\hline Glycyphagus ornatus & 99 & 0.59 & 11 & 7.33 \\
\hline Glycyphagus privatus & 5 & 0.03 & 2 & 1.33 \\
\hline Ctenoglyphus plumiger & 212 & 1.27 & 16 & 10.66 \\
\hline Ctenoglyphus canestrinii & 14 & 0.08 & 5 & 3.33 \\
\hline Diamesoglyphus intermedius & 5 & 0.03 & 3 & 2.00 \\
\hline Chortoglyphus arcuatus & 533 & 3.19 & 30 & 20.00 \\
\hline Gymnoglyphus longior & 71 & 0.42 & 13 & 8.66 \\
\hline Hirstia chelidonis & 15 & 0.09 & 5 & 3.33 \\
\hline Suidasia nesbitti & 2 & 0.01 & 2 & 1.33 \\
\hline Calvolia sp. & 9 & 0.05 & 4 & 2.66 \\
\hline Oribatida (sensu lato) & 6 & 0.04 & 5 & 3.33 \\
\hline Cheyletidae & 1186 & 7.09 & 109 & 72.66 \\
\hline Tydeidae & 3 & 0.02 & 1 & 0.66 \\
\hline Cunaxidae & 32 & 0.19 & 7 & 4.66 \\
\hline Heterostigmatina & 11 & 0.07 & 4 & 2.66 \\
\hline Prostigmata (other) & 6 & 0.04 & 4 & 2.66 \\
\hline Mesostigmata & 235 & 1.41 & 47 & 31.33 \\
\hline ACARI (total) & 16,719 & 100 & 150 & 100 \\
\hline
\end{tabular}

$N$ number of mite specimens, $n$ number of positive samples, $D(\%)$ percent of total count of mites collected, $F(\%)$ percent of the total number of samples positive for mites $(n=150)$

pigsties, barns and poultry houses $\left(\chi^{2}=13.9,7.25,22.22\right.$ and 40.96; $\left.p \leq 0.0071\right)$. It was also significantly more frequent in pigsties than in poultry houses $\left(\chi^{2}=22.37 ; p \leq 0.00001\right)$ and barns $\left(\chi^{2}=7.24 ; p=0.0071\right)$, whereas differences in frequency of $A$. siro in pigsties and cowsheds were not significant $(p=0.16)$. Moreover, $A$. siro was significantly more 


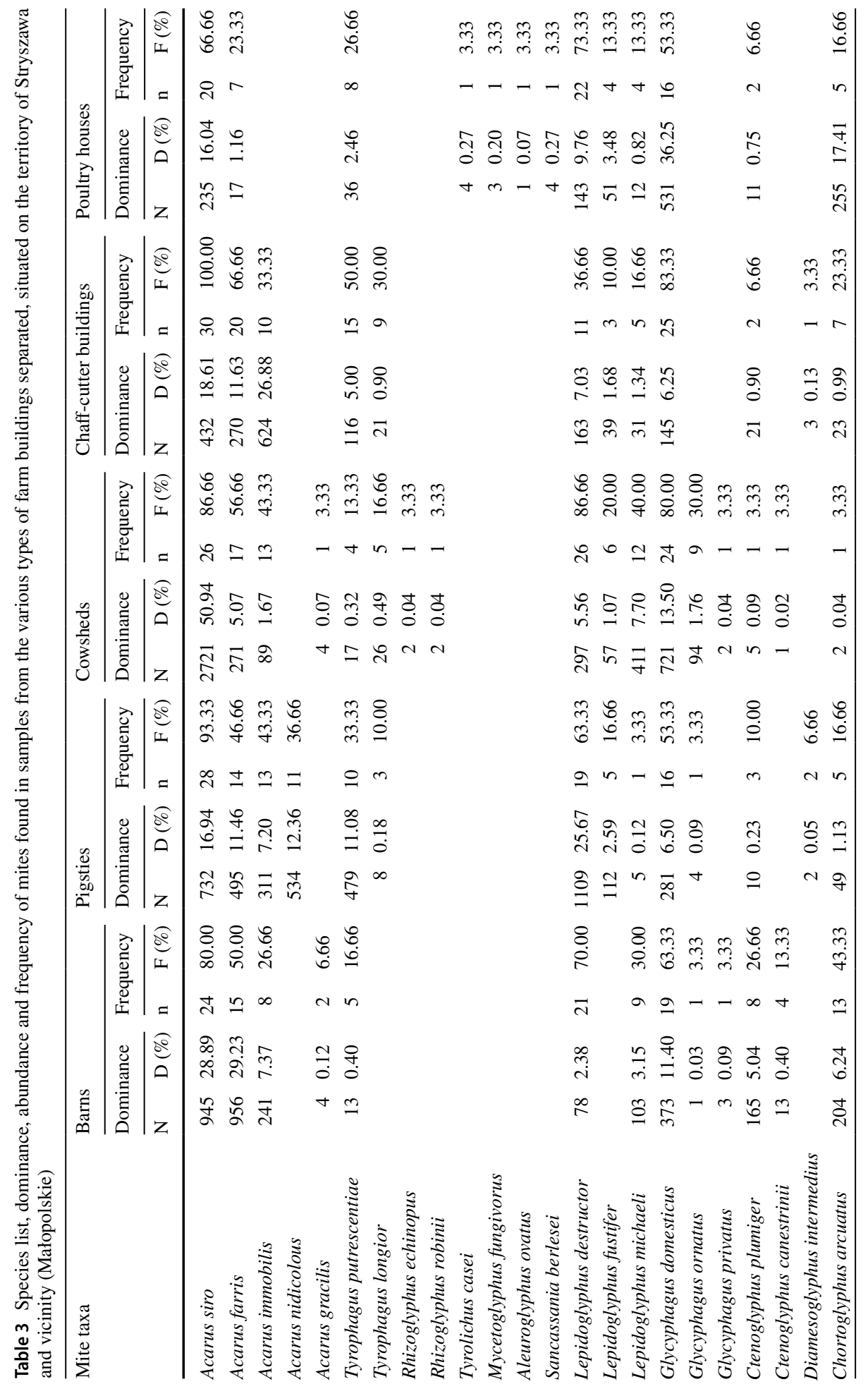




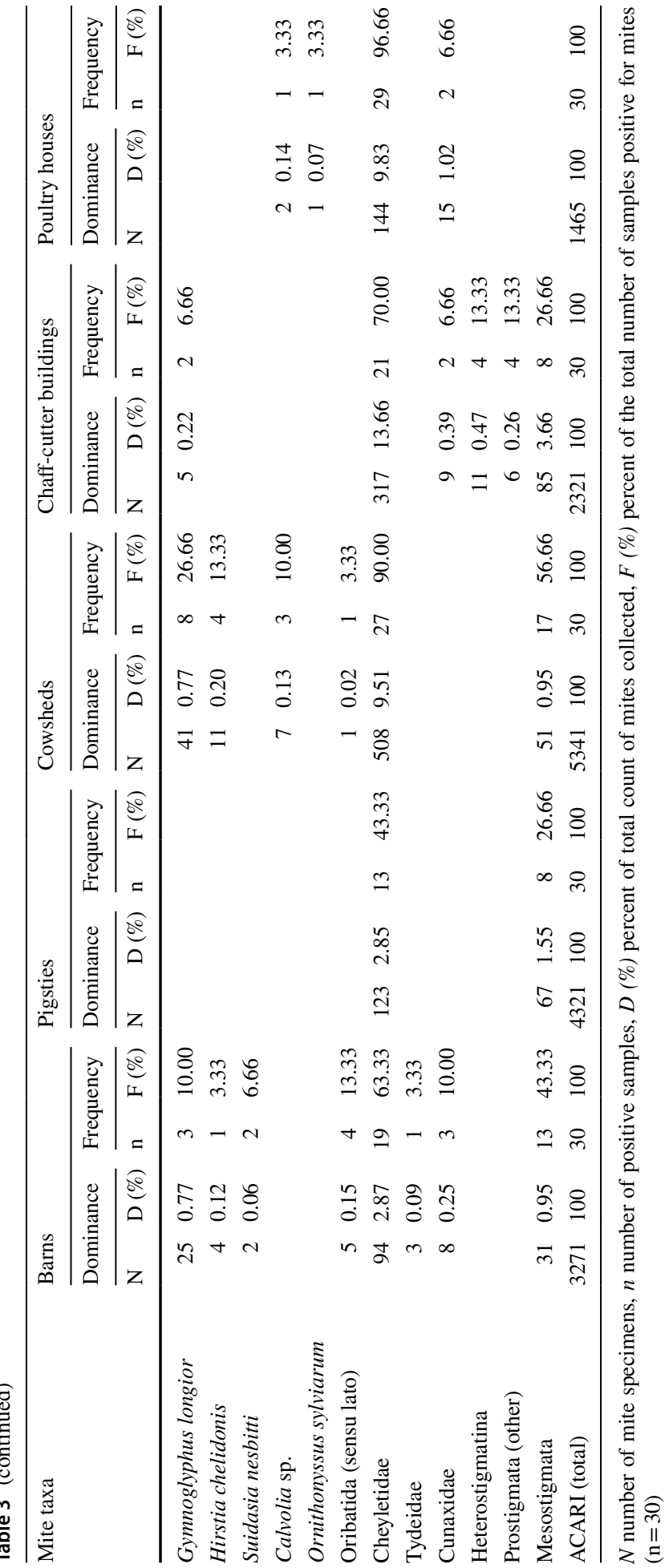


Table 4 Abundance of the most important allergenic mites in the particular farm buildings examined on the territory of Stryszawa and vicinity (Małopolskie)

\begin{tabular}{|c|c|c|c|c|c|c|c|c|c|c|}
\hline \multirow[t]{2}{*}{ Mites } & \multicolumn{2}{|l|}{ Barns } & \multicolumn{2}{|c|}{ Pigsties } & \multicolumn{2}{|c|}{ Cowsheds } & \multicolumn{2}{|c|}{$\begin{array}{l}\text { Chaff-cutter } \\
\text { buildings }\end{array}$} & \multicolumn{2}{|c|}{$\begin{array}{l}\text { Poultry } \\
\text { houses }\end{array}$} \\
\hline & M & $\mathrm{N} / \mathrm{S}$ & M & $\mathrm{N} / \mathrm{S}$ & M & $\mathrm{N} / \mathrm{S}$ & M & $\mathrm{N} / \mathrm{S}$ & M & $\mathrm{N} / \mathrm{S}$ \\
\hline Acarus siro & 10.78 & 39.38 & 8.44 & 26.14 & 30.15 & 104.65 & 4.07 & 14.4 & 2.58 & 11.75 \\
\hline Acarus farris & 10.90 & 63.73 & 5.81 & 35.36 & 2.73 & 15.94 & 3.05 & 13.5 & 0.16 & 2.43 \\
\hline Acarus immobilis & 2.74 & 30.13 & 3.23 & 23.92 & 0.89 & 6.85 & 7.06 & 62.4 & & \\
\hline Tyrophagus longior & & & 0.07 & 2.67 & 0.31 & 5.2 & 0.23 & 2.33 & & \\
\hline Tyrophagus putrescentiae & 0.68 & 2.6 & 7.03 & 47.9 & 1.01 & 4.25 & 1.30 & 7.73 & 0.38 & 4.5 \\
\hline Lepidoglyphus michaeli & 0.82 & 11.4 & 0.05 & 5.0 & 3.78 & 34.25 & 0.34 & 6.2 & 0.66 & 3.0 \\
\hline Lepidoglyphus destructor & 0.63 & 3.71 & 12.73 & 58.37 & 2.84 & 11.42 & 1.75 & 14.82 & 1.32 & 6.5 \\
\hline Lepidoglyphus fustifer & & & 6.57 & 22.4 & 3.17 & 9.5 & 2.20 & 13.0 & 2.80 & 12.75 \\
\hline Glycyphagus domesticus & 4.11 & 19.63 & 3.28 & 17.56 & 8.01 & 30.04 & 1.64 & 5.8 & 5.82 & 33.19 \\
\hline Glycyphagus ornatus & & & 0.06 & 4.0 & 1.06 & 10.44 & & & & \\
\hline Ctenoglyphus plumiger & 1.88 & 20.62 & & & 0.05 & 5.0 & & & 0.11 & 5.5 \\
\hline Chortoglyphus arcuatus & 2.05 & 15.69 & 0.53 & 9.8 & 0.11 & 2.0 & 0.06 & 3.29 & 2.80 & 51.0 \\
\hline Gymnoglyphus longior & 0.27 & 8.33 & & & 2.23 & 5.13 & 0.05 & 2.5 & & \\
\hline Hirstia chelidonis & 0.05 & 4.0 & & & 0.61 & 2.75 & & & & \\
\hline Cheyletidae & 0.57 & 4.95 & 1.11 & 9.46 & 3.89 & 18.81 & 2.71 & 15.09 & 0.66 & 4.97 \\
\hline
\end{tabular}

$M$ mean number of mites per $g$ of sample, $N / S$ number of mites per sample

frequent in cowsheds than in poultry houses $\left(\chi^{2}=12.3 ; p=0.0005\right)$, and more in barns than in poultry houses $\left(\chi^{2}=4.97 ; p=0.026\right)$, whereas the difference in frequency of $A$. siro in cowsheds vs. barns was not significant $\left(\chi^{2}=1.78 ; p=0.18\right)$ (Table 3$)$.

Lepidopglyphus destructor occurred much less frequently in chaff-cutter buildings than in the remaining types of farm buildings examined ( $p \leq 0.00001$, in all cases). Moreover, it was more frequent in cowsheds $(87 \%)$ than in poultry houses $\left(\chi^{2}=6.13, p=0.013\right)$, barns $\left(\chi^{2}=8.6, p=0.0034\right)$ and pigsties $\left(\chi^{2}=15.36, p=0.0001\right)$. It was also more frequent in poultry houses and barns than in pigsties but these differences were not significant $\left(\chi^{2}=2.3\right.$ and $1.1, p=0.13$ and 0.29 , respectively) (Tables $2,3,4$ ).

Glycyphagus domesticus occurred most frequently in chaff-cutter buildings (83\% positive samples) and cowsheds (80\%) (Tables 2, 3, 4). It was more frequently found in chaffcutter buildings and cowsheds than in the remaining types of farm buildings sampled $(p<0.01$, in all cases). The difference in frequency in barns $(63 \%)$, poultry houses $(53 \%)$ and pigsties $(53 \%)$ was not significant $\left(\chi^{2}=2.05, p=0.15\right)$ (Tables 3,4$)$.

\section{Mite fauna in barns}

In total 3271 mites were collected from barns, including 16 species from the cohort Astigmatina (Sarcoptiformes, Oribatida) (Tables 1, 3). Mite fauna from barns was dominated by two species of the genus Acarus: A. farris (29.2\%) and A. siro (28.9\%) (Astigmatina, Acaridae). Also numerous were G. domesticus (11.4\%), C. arcuatus (6.2\%) and C. plumiger $(5.0 \%)$ from the superfamily Glycyphagoidea, and the acarid A. immobilis $(7.4 \%)$ (Table 3). These mite species were also most abundant per g dust and per sample (Table 4). 
Among the less numerous remaining astigmatid mites were some allergenic taxa, as $L$. michaeli and L. destructor (Glycyphagidae), T. putrescentiae (Acaridae), G. longior and $H$. chelidonis (Pyroglyphidae), and Suidasia nesbitti (Suidasiidae) (Tables 3, 4). An important part of the non-astigmatid mites constituted predaceous and allergenic mites of the family Cheyletidae (Prostigmata) (2.3\% of mites collected from barns). Mesostigmata constituted only $0.95 \%$ of mites collected.

\section{Mite fauna in pigsties}

In total 4321 mites were collected from the pigsties (Tables 1, 3). Lepidopglyphus destructor (Glycyphagidae) was predominant (approx. $25.7 \%$ of the total count), followed by the acarids A. siro (16.9\%), A. nidicolous (12.4\%), A. farris (11.5\%), T. putrescentiae (11.1\%) and $A$. immobilis (7.2\%). The other eight species of astigmatid mites found were T. longior (Acaridae), L. fustifer, L. michaeli, G. domesticus, G. ornatus, C. plumiger, D. intermedius (Glycyphagidae) and C. arcuatus (Chortoglyphidae) (Table 3). Among the remaining mite taxa cheyletids were most numerous ( $2.85 \%$ of all mites collected from these pigsties).

\section{Mite fauna in cowsheds}

Acarofauna of cowsheds was also dominated by astigmatid mites: of the 5341 mites isolated from cowsheds, 4781 were of the cohort Astigmatina (89.5\%) (Table 3). Twenty astigmatid species were found: A. siro, A. farris, A. immobilis, Acarus gracilis, T. longior, T. putrescentiae, Rhizoglyphus robini, R. echinopus (Acaridae), G. domesticus, G. ornatus, G. privatus, L. michaeli, L. destructor, L. fustifer, C. canestrinii (Glycyphagidae), C. arcuatus (Chortoglyphidae), G. longior, H. chelidonis (Pyroglyphidae) and Calvolia sp. (Winterschmidtiidae) (Table 3).

Acarus siro was the dominant species (50.9\%) and the most abundant mite per sample and per g, whereas $G$. domesticus was the most numerous glycyphagid species $(13.5 \%)$ (Tables 3, 4). Numerous among the astigmatid mites were A. farris (5.1\%), L. michaeli (7.7\%) and L. destructor (5.6\%). Cheyletid mites constituted $9.5 \%$ of the total count of mites from the examined cowsheds (Table 3 ).

\section{Mite fauna in chaff-cutter buildings}

Acarofauna from chaff-cutter buildings was also dominated by the Acaridae: of the 2321 mites isolated (Tables 1, 3), 1893 specimens were from the cohort Astigmatina (81.6\% of all mites collected from chaff-cutter buildings) and 1463 mites were acarids (63.0\% of the total count). These mites were also most abundant both per sample and per g (Table 4). Among Astigmatina 13 species were found: A. siro, A. farris, A. immobilis, T. putrescentiae, T. longior (Acaridae), L. fustifer, L. destructor, C. plumiger, D. intermedius (Glycyphagidae), C. arcuatus (Chortoglyphidae) and G. longior (Pyroglyphidae) (Table 3). Acarus immobilis was the dominant and most abundant species, both per $\mathrm{g}$ and per sample (Tables 3,4 ). Species of the $A$. siro complex constituted $57.1 \%$ of the total count of mites collected from the chaff-cutter buildings, including A. siro (18.6\%) and A. farris (11.6\%). Among the other numerous mites were L. destructor (7.0\%), G. domesticus (6.3\%), T. putrescentiae (5.0\%), and members of the family Cheyletidae (13.7\%) (Table 3). 


\section{Mite fauna in poultry houses}

Among 1465 mites collected from poultry houses, G. domesticus was predominant $(36.3 \%$ of the total count), followed by C. arcuatus (17.4\%), A. siro (16.0\%), cheyletids $(9.8 \%)$ and L. destructor $(9.8 \%)$ (Table 3 ). In total 14 species of astigmatid mites were found in poultry houses, including also A. farris, T. putrescentiae, T. casei, M. fungivorus, A. ovatus, Sancassania berlesei (Acaridae), L. fustifer, L. michaeli, C. plumiger (Glycyphagidae) and Calvolia (Winterschmidtiidae) (Table 3). Members of the superfamily Glycyphagoidea were distinctly more abundant than the remaining astigmatid mites and constituted approximately $68.5 \%$ of all mites collected (Table 3 ). Among the mesostigmatid mites, one specimen of Ornithonyssus sylviarum was found (Table 3).

\section{Abundance of mites in the examined farm buildings}

The mean number of all mites collected per $g$ of sample constituted 17.55. The number of mites per g sample was varied considerably among mite species and among particular types of farm buildings (Table 4). The most abundant species were A. siro (especially in cowsheds, barns and pigsties), A. farris (in barns) and L. destructor (mainly in pigsties) (Table 4). The total number of mites per sample constituted 278.65 (on average 111.5). The number of mites per sample was highest for cowsheds (198.0) and lowest for poultry houses (48.8) and chaff-cutter buildings (77.4) (Table 4). The most abundant species of mites per sample were A. siro (especially in cowsheds and barns), A. farris (in barns and pigsties), $L$. destructor (mainly in pigsties) and $G$. domesticus (mainly in barns). The remaining allergenic mites were distinctly less abundant both per sample and per g (Table 4).

\section{Discussion}

Agricultural work is considered to be a major risk factor for occupational diseases (Berger et al. 2005). All mites should be regarded as a potential source of mite allergens in environments associated with activity of man, not only in dwellings (Fain et al. 1990; Solarz 2006; Stejskal and Hubert 2008; Colloff 2009). So far, many groups of mites were not reported as occupational biohazards for humans (Arlian 2002). The greatest exposure to storage mites usually occurs in an agricultural setting where allergies to these mites are of major importance (van Hage-Hamsten and Johansson 1998; Arlian 2002; Cichecka et al. 2006). For the urban population, sensitivity to particular species of storage mites and their cross-reactivity with pyroglyphid dust mites is usually not important. Generally, the exposure of city people to storage mites is minimal (Solarz 2010). For farmers and other agricultural workers both storage and house dust mites may act as inhalant allergens. Therefore, for people living in (sub)agricultural settlements, sensitivity to various species of domestic and storage mites and cross-reactivity between species may be of clinical significance (Arlian 2002; Cichecka et al. 2006). On the other hand, sensitization to storage mites in urban dwellers has been reported in Spain, Denmark, Germany, Croatia, Poland and USA (Ebner et al. 1994; Garcia-Robaina et al. 1996; Macan et al. 1998; Gislason and Gislason 1999; Kanceljak-Macan et al. 2000; Arlian 2002; Solarz et al. 2008). Sensitization to T. putrescentiae and $L$. destructor is present in the urban population of Upper Silesia in similar proportions as to the Dermatophagoides spp. (Szilman et al. 2004; Cichecka et al. 2006; Solarz et al. 2008; Asman et al. 2009). Our previous studies suggest that allergenic mites belonging 
to the Acaridae, Glycyphagidae and Chortoglyphidae should be considered in Poland as potential occupational risk factors contributing to the occurrence of respiratory and dermal diseases among workers of zoos, coal-miners, bird breeders and farmers (Solarz and Solarz 1995; Solarz et al. 2004a, b, 1997; Cichecka et al. 2006).

The natural sources of allergenic mites in stores are still not well known. It has been suggested that the majority of the mite population is brought from the cultivated field into the stores, and that the open field is the main source of storage mites (Hallas and Iversen 1996), whereas bird nests are less important (Solarz et al. 2007).

The investigated farm buildings are typical for A. farris, T. longior, T. putrescentiae, Lepidoglyphus spp. and Glycyphagus spp. It is commonly known that A. siro, T. putrescentiae, T. casei, M. fungivorus, A. ovatus, Sancassania spp. and Rhizoglyphus spp. occur in various stored food products (Hughes 1976; Solarz 2012). Tyrophagus longior usually was the dominant species in haystacks and grainstacks standing in open fields (Hughes 1976). Moreover, T. longior, T. putrescentiae, L. destructor, Tarsonemus spp. and Cheyletidae were frequently found on farms in stored hay and straw (Hallas 1981; Terho et al. 1982, 1985; Hallas and Gudmundsson 1985; Korsgaard et al. 1985; Hallas and Solberg 1989; Hallas et al. 1991; Franz et al. 1997; Solarz et al. 1997; Boström et al. 1997; Mehl 1998; de Saint; Georges-Gridelet et al. 2003). All these mites are considered as allergenic (Revsbech and Andersen 1987, 1989; Luczynska et al. 1990; Armentia et al. 1994; Szilman et al. 2004; Stejskal and Hubert 2008; Asman et al. 2009). The species T. putrescentiae, A. siro complex, G. domesticus and L. destructor, which have actually been found in farming environments, are the most often studied allergenic mites of the cohort Astigmatina (van Hage-Hamsten et al. 1992; Kronqvist et al. 2000; Eriksson et al. 1998, 2001; Arlian 2002; Cichecka et al. 2006; Solarz et al. 2007; Stejskal and Hubert 2008). As mentioned above, these mites produce multiple allergens (Arlian 2002) and may cause occupational allergies. Several tarsonemid species are also considered as allergenic-some authors believe them to be a significant group of allergenic domestic mites (Korsgaard and Hallas 1979; Hallas and Korsgaard 1997).

The stated prevalence of cheyletids and glycyphagids in the farming environment is not in accordance with earlier data by Hallas (1981), Terho et al. (1982) and Solarz et al. (1997). The abundance of acarids was distinctly higher than that found in Solarnia (Lubliniec vicinity), in the vicinity of Kokotek and in Lesko (Krosno province) (Solarz et al. 1997), and it was similar as the abundance in dust samples from byres, hay and grain stores of 11 farms in Eastern Finland (Terho et al. 1982, 1985) and in samples of dust and organic debris from coal mines in Upper Silesia (Solarz and Solarz 1995) or in storage facilities in Iran (de Saint Georges-Gridelet et al. 2003). The number of astigmatid mite species found in this study was higher than in farming environments in Finland (Terho et al. 1982) and Iceland (Hallas 1981; Hallas and Gudmundsson 1985) or in coal mines in Poland (Solarz and Solarz 1995), and it was similar as in farm buildings examined earlier in Poland (Solarz et al. 1997; Solarz 2012) or in Iran (de Saint Georges-Gridelet et al. 2003). Some species of the family Pyroglyphidae (G. longior, H. chelidonis and Dermatophagoides farinae) have been found in farming environments in UK, Switzerland, Israel, Iran, USA, Canada (Hughes 1976; Fain et al. 1990; Mumcuoglu and Lutsky 1990; de Saint; Georges-Gridelet et al. 2003) and also in Poland (Solarz et al. 1997; Solarz 2012).

The present results confirm the occurrence of allergenic mites in cowsheds, barns, chaffcutter buildings and poultry houses (Hughes 1976; Terho et al. 1982; Fain et al. 1990; Mumcuoglu and Lutsky 1990; Solarz et al. 1997; Stejskal and Hubert 2008), and reveal the occurrence of these mites in pigsties. Thus, all these locations should be regarded as a potential source of storage mite allergens in the farming environment. As the occurrence 
and concentration of mites in samples from different farm buildings may vary to a considerable extent, further studies are highly desirable.

Open Access This article is distributed under the terms of the Creative Commons Attribution 4.0 International License (http://creativecommons.org/licenses/by/4.0/), which permits unrestricted use, distribution, and reproduction in any medium, provided you give appropriate credit to the original author(s) and the source, provide a link to the Creative Commons license, and indicate if changes were made.

\section{References}

Arlian LG (2002) Arthropod allergens and human health. Annu Rev Entomol 47:395-433

Armentia A, Fernández A, Pérez-Santos C, de la Fuente R, Sánchez P, Sanchís F, Méndez J, Stolle R (1994) Occupational allergy to mites in salty ham, chorizo and cheese. Allergol et Immunopathol 22:152-154

Asman M, Solarz K, Szilman P, Szilman E (2009) Analysis of expression of the allergen Mag 3 in the storage species-Tyrophagus putrescentiae (Acari: Astigmata: Acaridae). In: Buczek A, Błaszak C (eds) Arthropods. Invasions and their control. Akapit, Lublin, pp 165-172

Baker AS (1999) Mites and ticks of domesic animals. An identification guide and information source. The Stationery Office, London, p 240

Berger I, Schierl R, Ochmann U, Egger U, Scharrer E, Nowak D (2005) Concentrations of dust, allergens and endotoxin in stables, living rooms and mattresses from cattle farmers in Southern Bavaria. Ann Agric Environ Med 12:101-107

Boström S, Johansson E, Härfast B, Lundqvist L, Bäckman I, von Rosen E, van Hage-Hamsten M (1997) Characterization of the mite fauna (Acari) in Swedish barn dust. Int J Acarol 23:127-132

Cichecka E, Maniurka H, Szilman P, Szilman E, Solarz K, Sieroń AL (2006) Sensitization to storage mites in urban and subagricultural population of Upper Silesia. In: Buczek A, Błaszak C (eds) Arthropods. Epidemiological importance. Koliber, Lublin, pp 287-293

Colloff MJ (2009) Dust mites. CSIRO Publishing, Collingwood, p 600

de S Georges-Gridelet, Wauthy D, Ardeshir G, Grootaert F, Tirry P L (2003) Mite community of storage facilities in Iran. Bull Inst R Sc Nat Belg Entomol 73:67-76

Ebner C, Feldner H, Ebner H, Kraft D (1994) Sensitization to storage mites in house dust mite (Dermatophagoides pteronyssinus) allergic patients. Comparison of a rural and an urban population. Clin Exp Allergy 24:347-352

Eriksson TLJ, Johansson E, Whitley P, Schmidt M, Elsayed S, van Hage-Hamsten M (1998) Cloning and characterisation of a group II allergen from the dust mite Tyrophagus putrescentiae. Eur J Biochem 251:443-447

Eriksson TLJ, Rasool O, Huecas S, Whitley P, Crameri R, Appenzeller U, Gafvelin G, van Hage-Hamsten M (2001) Cloning of three new allergenns from the dust mite Lepidoglyphus destructor using phage surface display technology. Eur J Biochem 268:287-294

Fain A, Guerin B, Hart BJ (1990) Mites and allergic disease. Allerbio, Varennes en Argonne

Fan QH, Zhang ZQ (2007) Tyrophagus (Acari: Astigmata: Acaridae). Manaaki Whenua Press, Lincoln

Franz JT, Masuch G, Musken H, Bergmann KC (1997) Mite fauna in German farms. Allergy 52:1233-1237

Garcia-Robaina JC, Torre-Morin F, Bonnet-Moreno CG, Antonin-Arias J, Perez-Santos C, Sanchez-Covisa A (1996) House dust mites and Der p 1 in Tenerife (Canary Islands, Spain): the relative importance of other non-Dermatophagoides spp. mites. Allergol Immunopathol 24:135-138

Gislason D, Gislason T (1999) IgE-mediated allergy to Lepidoglyphus destructor in an urban populationan epidemic study. Short communication. Allergy 54:878-883

Hallas TE (1981) Mites of stored hay in Iceland. J Agr Res Icel 13:61-67

Hallas TE, Gudmundsson B (1985) Mites of stored hay in Iceland. Related to quality of hay and the storage duration. JAgr Res Icel 17:31-37

Hallas TE, Iversen M (1996) Sources of exposure to storage mites in the farming environment. Ann Agric Environ Med 3(1):9-12

Hallas TE, Korsgaard J (1997) Systematic variations in the appearance of house-dust mites (Dermatophagoides spp.), house mites (Glycyphagus domesticus) and of Tarsonemus sp. in dust samples from dwellings. Rev Esp Alergol Immunol Clin 12:73-177

Hallas TE, Solberg H (1989) Mites of stored hay on the Faroe Islands (Acari). Ent Meddr 57(3):151-155

Hallas TE, Iversen M, Korsgaard J, Dahl R (1991) Number of mites in stored grain, straw and hay related to the age of the substrate (Acari). Ent Meddr 59:57-60 
Hughes AM (1976) The mites of stored food and houses. HMSO, London, p 400

Kanceljak-Macan B, Macan J, Buneta L, Milkovic-Kraus S (2000) Sensitization to nonpyroglyphid mites in urban population of Croatia. Croatian Med J 41:54-57

Korsgaard J, Hallas T (1979) Tarsonemid mites in Danish house dust. Allergy 34:225-232

Korsgaard J, Dahl R, Iversen M, Hallas T (1985) Storage mites as a cause of bronchial asthma in Denmark. Allergol Immunopathol 13:143-149

Krantz GW, Walter DE (2009) A manual of acarology, 3rd edn. Texas Tech University Press, Lubbock, p 807

Kronqvist M, Johansson E, Magnusson CGM, Olsson S, Eriksson TLJ, Gafvelin G, van Hage-Hamsten M (2000) Skin prick test and serological analysis with recombinant group 2 allergens of the dust mites $L$. destructor and T. putrescentiae. Clin Exp Allergy 30:670-676

Luczynska CM, Griffin P, Davies RJ, Topping MD (1990) Prevalence of specific IgE to storage mites $(A$. siro, L. destructor and T. longior) in an urban population and cross-reactivity with the house dust mite (D. pteronyssinus). Clin Exp Allergy 20:403-406

Macan J, Kanceljak-Macan B, Zuskin E, Milkovic-Kraus S (1998) Sensitization to storage mites in urban working environment. Arch Ind Hyg Toxicol 49:27-32

Mehl R (1998) Occcurrence of mites in Norway and the rest of Scandinavia. Allergy 53(Suppl 48):28-35

Mumcuoglu KY, Lutsky I (1990) A prevalence survey of poultry house mites in Israel. Acarologia 31:51-56

Pike AJ, Wickens K (2008) The House Dust Mite and Storage Mite fauna of New Zealand dwellings. N Z Entomol 31:17-22

Revsbech P, Andersen G (1987) Storage mite allergy among grain elevator workers. Allergy 42:423-429

Revsbech P, Andersen G (1989) Diurnal variation in peak expiratory flow rate among grain elevator workers. Br J Ind Med 46:566-569

Revsbech P, Dueholm M (1990) Storage mite allergy among bakers. Allergy 45:204-208

Sánchez-Ramos I, Hernández CA, Castanera P, Ortego F (2004) Proteolytic activities in body and faecal extracts of the storage mite, Acarus farris. Med Vet Entomol 18:378-386

Sánchez-Ramos I, Álvarez-Alfageme F, Castanera P (2007) Effects of relative humidity on development, fecundity and survival of three storage mites. Exp Appl Acarol 41:87-100

Solarz K (2006) Allergenic mites in habitats associated with man. Biol Lett 43:299-306

Solarz K (2010) Temporal changes in the composition of house-dust-mite fauna in Poland. Acta Zool Cracov 53:39-64

Solarz K (2012) House dust mites and storage mites (Acari: Oribatida: Astigmatina). Identification keys. Institut of Systematics and Evolution of Animals Polish Academy of Sciences, Cracow, p 120

Solarz K, Solarz D (1995) The allergenic mites in coal-mine dust from coal mines in Upper Silesia (Poland). Ann Agric Environ Med 3:49-55

Solarz K, Szilman P, Szilman E (1997) Preliminary study on the occurrence and species composition of astigmatic mites (Acari: Astigmata) in samples of dust, debris and residues from farming environments in Poland. Ann Agric Environ Med 4:249-252

Solarz K, Szilman P, Szilman E (2004a) Occupational exposure to allergenic mites in a Polish Zoo. Ann Agric Environ Med 11:27-33

Solarz K, Szilman P, Szilman E, Krzak M, Jagła A (2004b) Some allergenic species of astigmatid mites (Acari, Astigmata) from different synanthropic environments in southern Poland. Acta Zool Cracov 47:125-145

Solarz K, Seńczuk L, Maniurka H, Cichecka E, Peszke M (2007) Comparisons of the allergenic mite prevalence in dwellings and certain outdoor environments of the Upper Silesia (Southwest Poland). Int J Hyg Environ Health 210:715-724

Solarz K, Szilman P, Szilman E, Asman M, Sieroń AL (2008) Sensitization to Lepidoglyphus destructor in urban and rural populations of Upper Silesia. Further studies. In: Buczek A, Błaszak C (eds) Arthropods. Influence on host. Akapit, Lublin, pp 57-61

Stejskal V, Hubert J (2008) Risk of occupational allergy to stored grain arthropods and false pest-risk perception in Czech grain stores. Ann Agric Environ Med 15:29-35

Szilman E, Szilman P, Solarz K, Brewczyński P, Sieroń AL (2004) Sensitization to the storage mite Tyrophagus putrescentiae in urban population of Upper Silesia (Poland). Wiad Parazytol 50(3):471-476

Terho EO, Leskinen L, Husman K, Kärenlampi L (1982) Occurrence of storage mites in Finnish farming environments. Allergy 37:15-19

Terho EO, Husman K, Vohlonen I, Rautalahti M, Tukiainen H (1985) Allergy to storage mites or cow dander as a cause of rhinitis among Finnish dairy farmers. Allergy 40:23-26

van Hage-Hamsten M, Johansson SGO (1998) Clinical and immunologic aspects of storage mite allergy. Allergy 53(Suppl 48):49-53 
van Hage-Hamsten M, Scheynius A, Harfast B, Wiren A, Johansson SGO (1992) Localization of allergens in the domestic mite Lepidoglyphus destructor. Clin Exp Allergy 22:251-256

Wong SF, Chong AL, Mak JW, Tan J, Ling SJ, Ho MT (2011) Molecular identification of house dust mites and storage mites. Exp Appl Acarol 55:123-133

Zhang ZQ, Fan QH (2005) Revision of Tyrophagus Oudemans. In: (Acari: Acaridae) of New Zealand and Australia. Landcare Research New Zealand Ltd, Auckland, New Zealand

Publisher's Note Springer Nature remains neutral with regard to jurisdictional claims in published maps and institutional affiliations. 